\title{
Exploring Engagement with Robots among Persons with Neurodevelopmental Disorders
}

\author{
Eleonora Aida Beccaluva, Andrea Bonarini, Roberto Cerabolini, Francesco Clasadonte, \\ Franca Garzotto, Mirko Gelsomini, Vito Antonio Iannelli, Francesco Monaco, Leonardo Viola
}

\begin{abstract}
Our research explores social robots as learning tools for persons with Neurodevelopmental Disorder (NDD). The paper reports an empirical study that investigates engagement as a prerequisite for any learning process of NDD subjects. The study involved 5 persons in this target group and three robots (two research products developed at our lab, and a commercial one), which were used in sequence during individual therapeutic sessions at a care center. The results enable us to compare the engagement effects of different social robots and improves our understanding of the behavior of persons with NDD during robotic experiences.
\end{abstract}

\section{INTRODUCTION}

Neurodevelopmental Disorders (NDD) are a group of conditions with onset in the developmental period that are characterized by a wide spectrum of (frequently co-occurring) deficits and produce severe impairments in personal, social, academic or occupational functioning. Such conditions range from very specific limitations of learning and control of executive functions to impairments in social skills and intelligence. Social robots are thought to have an enormous potential as learning tools for subjects with NDD to help them to develop skills needed for independent living. Robotic interaction in relationship to this target group has been explored in many studies. Yet, we have a limited understanding of the learning process that takes place in subjects with NDD while interacting with robots.

Our research explores the above process from a specific angle, focusing on the engagement phase. Engagement is a broad term and there is no agreement on the definition and operationalization of the construct [19]. We embrace the definition by Chapman [4], who stated that "... something that 'engages' us is something that draws us in, that attracts and holds our attention" (p. 3).

Engagement is widely acknowledged learning facilitator [19]. For subjects with NDD, the role of engagement is even stronger. The deficits associated to NDD create a persistent state of insecurity and uncertainty, a tendency to withdrawal and self-inhibition, and a difficulty to stay focused on something for a prolonged time, which hinders the willingness and capability to be involved in a task and to act upon the associated objects. Among subjects with NDD, reaching and maintaining a state of engagement is a precondition for any learning activity [12].

Andrea Bonarini, Francesco Clasadonte, Franca Garzotto, Mirko Gelsomini, Francesco Monaco, Leonardo Viola are with Politecnico di Milano, Department of Electronics, Information and Bioengineering, [name.surname]@polimi.it

Eleonora Aida Beccaluva, Roberto Cerabolini, Vito Antonio Iannelli are with Fraternità and Amicizia Care Center, Milan,

[name.surname]@fraternitaeamicizia.it
This paper describes an exploratory study that is part a wider research devoted to identify appropriate instruments and strategies to include interaction with robots in the treatment of persons with NDD.

The study was performed in collaboration with a local care center and involved 5 persons with different forms of disability in the NDD spectrum. We observed their spontaneous interaction with three robotic companions (two research products developed at our lab, and a commercial one) that according to prior studies have a potential in NDD interventions. We explored the engagement process that took place among participants and compared the engagement capability of these three robots

The study increases our knowledge on the behavior of persons with NDD during the very initial stage of a robotic experience. We also offer a contribution from a methodological perspective. The paper introduces an operationalization of the construct of engagement that considers the characteristics of robotic interaction and the profile of each specific person, which may help other researchers in the SAR field to design similar studies.

\section{RELATED WORK}

A wide number of existing studies in the field of socially assistive robotics (SAR) ([10]) investigate robotic interaction among subjects with NDD. Many studies involve people with ADHD (Attention Deficit - Hyperactivity Disorder) [35] [21] or ASD (Autistic Spectrum Disorder) ([1] [7] [3] [6] [13] [30] [8] [17] [23] [11] [31] [34] [25][27]), and attempt to evaluate the benefits of robots to achieve specific skills. In most cases, the interaction with the robot focuses on a single type of tasks that are designed to achieve a specific therapeutic goal and are framed in a path of actions and a pre-planned sequence of stimuli. The works reported in [9] [28] [29], [18], [15], [24] investigate robotic companions as tools in socialization therapy for children with NDD. In [24], the authors focus on the development of imitation skills. The research described in [23] addresses communication or question answering capability. Few robots developed for NDD subjects (e.g., Teo [2]) sustain free play and support spontaneous, intrinsically motivated, unstructured interactions [20].

Several comparative studies explore robotic interaction for under different experimental conditions. Some of them consider interactive vs non-interactive versions of the same robots. For example Shibata et al. [33] compares the therapeutic effects in children of Paro "as a robot" against a control group working with Paro "as a stuffed object", i.e., with all interactive features turned off. Other studies consider the comparison among different robots with some similar characteristics, or between a robot and a human being. 
Michaud et al. [18] compared different mobile robots, such as Robota (a humanoid doll [36]) and Tito the Robot (another of their project) against a spherical robot (Roball). Douquette [9] compares a mobile robot (Tito) and a human being as imitation agents. He found that children with NDD imitated familiar body movements and gestures (e.g., raising arms or dancing) with the human mediator more than with the robot, however with the robot, the children demonstrated increased shared attention towards the robot and imitated facial expression (e.g. joy, sadness, angry) more with the robot than with the human mediator.

Any learning experience with a robot - no matter if goaloriented or based on "free play", i.e., spontaneous unstructured interaction [20] - would not be successful among persons with NDD if the robotic companion fails to engage them. Still, to our knowledge the engagement process per se has not studied in depth in the current research on SAR for NDD.

\section{EMPIRICAL STUDY}

\section{A. Research variables}

In order to operationalize the broad concept of engagement and define our research variables, we started from the definition of engagement process. We embrace the general model described in [19] to depict engaging experiences, which proposes an iterative process starting with an initial point of engagement followed by a period of sustained engagement, disengagement, and (possibly) reengagement. The behaviors associated to each component of this model are grounded on existing practices and assessment methods in NDD and have been identified by the specialists of our team.

We define the Point of Engagement as the subject's first manifestation of being attracted by the robot. It is measured by Initial Latency Time (Latency Time for short), i.e., the time between the positioning of a robot in the visual area of the subject and the subject's first signal of attention towards the robot.

The behavioral signals that indicate a Point of Engagement are not the same for all subjects but depend on the severity of the disorder and the individual characteristics of a person. For subjects with severe forms of ASD, the Point of Engagement corresponds to the first voluntary visual contact with the robot. Eye contact is often missing in autistic persons and when it takes place, this is considered an important communication act to express interest. For other subjects, looking at the robot is not necessarily an expression of interest; the Point of Engagement occurs at the first voluntary physical contact with the robot.

Sustained Engagement is the period during which the subject manifests the willingness of acting act upon with the robot and interacts with it.

Disengagement is the period during which the subject manifests no interest towards the robot.

Sustained Engagement and Disengagement are associated to a set of behaviors (Table I) that range from high engagement to strong disengagement. For example, if the subject "Interacts with a purpose, e.g., waves the robot, shakes it, or talks, expecting a reaction", this is considered a stronger manifestation of engagement than "Moves the robot into the personal space, and explores physical contact". If the subject "ignores to the robot and, when required to interact with it, pushes it away", this is interpreted as a stronger manifestation of disengagement that "does not pay attention to the robot".

The measurable variable associated to Sustained Engagement and Disengagement is Behavior Duration, i.e., the period during which a behavior is maintained.

TABLE I. ENGAGEMENT-DISENGAGEMENT BEHAVIORS

\begin{tabular}{|l|}
\hline Engagement Behaviors \\
\hline $\begin{array}{l}\text { Interacts with a purpose, e.g., waves the robot, shakes it, or talks, } \\
\text { expecting a reaction }\end{array}$ \\
\hline $\begin{array}{l}\text { Holds the robot with both hands and manifests an arousing of positive } \\
\text { emotions (e.g., laughs and smiles) }\end{array}$ \\
\hline $\begin{array}{l}\text { Grabs and hugs the robot with both hands and manifests positive } \\
\text { emotions (e.g., smiles) }\end{array}$ \\
\hline $\begin{array}{l}\text { Moves the robot into the personal space }(*), \text { and explores physical } \\
\text { contact }\end{array}$ \\
\hline $\begin{array}{l}\text { Sustains a visual contact with the robot and manifest minimal physical } \\
\text { contacts, e.g., touches and caresses }\end{array}$ \\
\hline Looks at the robot and sustains a visual contact with it \\
\hline Disengagement behaviors \\
\hline Doesn't pay attention to the robot \\
\hline Ignores the robot and manifests irritation or frustration \\
\hline Pushes the robot away \\
\hline $\begin{array}{l}\text { (*) Personal space is the region surrounding a person which is within the reach of } \\
\text { any limb of an individual, and they regard as psychologically theirs. [22] }\end{array}$ \\
\hline
\end{tabular}

\section{B. Instruments}

We considered three social robots named Teo, Sam, and Paro. Teo [2] and Sam [5] are research products from our lab. They have been designed in cooperation with NDD specialists to support both spontaneous interaction and goal-oriented tasks, and have been and evaluated in prior pilot studies involving children and adults with NDD. Paro is a well-known commercially available robot. Originally developed to relieve depression and anxiety in persons with dementia, Paro was experimented also in interventions with persons with a wider range of disabilities, including NDD [26] [16] [32]. The three robots have different structural, functional, and interaction features, but also a number of similar characteristics: a nonhumanoid shape; a soft structure with many tactile sensors to support manipulation based interaction; the capability of vibrating and emitting sound.

Teo (Fig. 1) is a soft mobile robot approximately $60 \mathrm{~cm}$ high that behave either autonomously or tele-operated by caregivers. Its egg-shaped body does not have any internal skeleton and is filled with polystyrene micro balls, which makes manipulation easy and pleasurable for subjects from 3 years old up to adults. Teo's sensorized body can distinguish among caresses, hugs, and two levels of violent punches or slaps. Depending on the intensity and dynamics of the body deformation induced by the physical contact, the manipulation produces stimuli that are intended to represent Teo's emotional states. For example, Teo becomes "Happy" when its body is softly caressed or touched and replies to manipulation by vibrating, rotating itself cheerfully, and moving around, while a green colored light LED strip slowly blinks. Teo wears a changeable hat that holds a set of big push-buttons. These are used as interaction affordances, to enable children to express choices or to answer questions. Buttons can be personalized by therapists by inserting cardboard tags inside, e.g., colors, numbers, realistic images or PCSs (Picture Communication Symbols commonly used in AAC Augmented Alternative 
Communication interventions [14]). Teo robot can sense the distance from the users and perform unconstrained movements in the space thanks to its triangular, holonomic (omnidirectional) base that is equipped with motors, batteries, electronics, a colored LED stripe, infrared and sonar distance sensors.

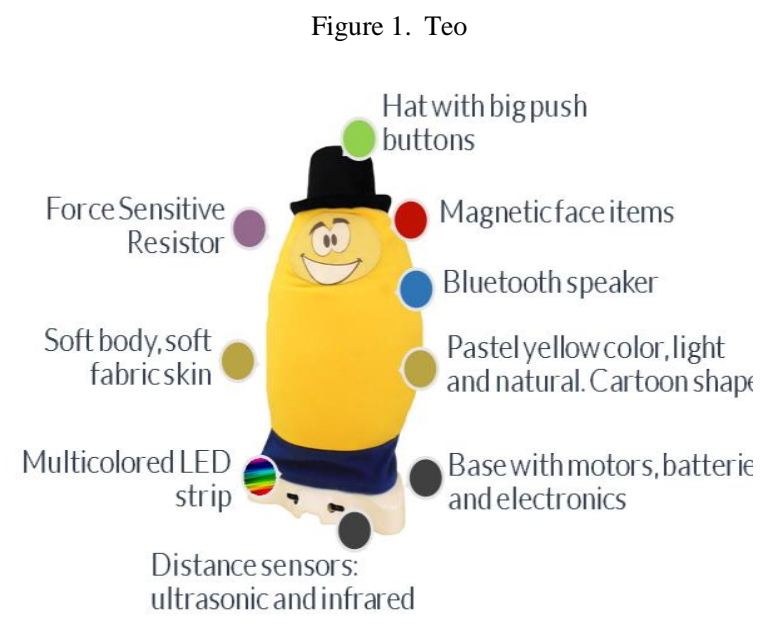

Sam (Fig. 2) is an interactive dolphin-shaped stuffed toy sized approximately $40 \times 20 \times 15 \mathrm{~cm}$. The robot's eyes and mouth are controlled by two motors; head, stomach, right and left fins are connected to four touch sensors; one LED strip is placed inside on the stomach and two LED strips are on the top of the body; a speaker and an RFID reader are embedded into the mouth. In response to user interaction the robot vibrates, opens/closes its eyes and mouth, play sounds and music, and emits (yellow-green-blue) light effects. Sam reacts to caresses, touches on its head, stomach and fins. For examples, if Sam is "sleeping" (eyes closed, snoring sounds), the user can wake it up by caressing it - Sam opens its eyes, emits yawns sounds and opens its mouth. Sam also reacts to the insertion of "cards" into its mouth. For example, it can be "fed" by placing into its mouth a card with a food image. Sam reacts with pleasurable sound and soft light effects if he likes the food (e.g., fish) and with a "voice" expressing disgust otherwise.

Figure 2. Sam

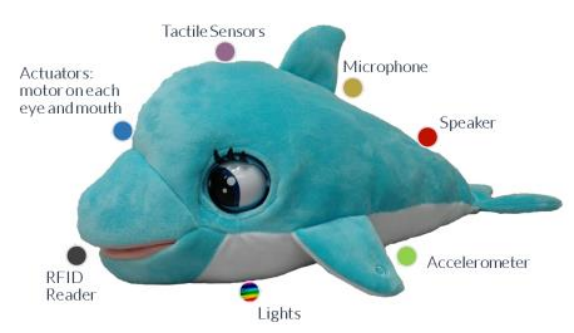

Paro (Fig. 3) is a commercial interactive robot shaped as a baby harp seal. Paro has an extremely pleasant and soft fur that makes people comfortable when manipulating it. Through different kinds of embedded devices like tactile, light, audition, temperature, and posture sensors, the robot can perceive the people and its environment. Paro has an autonomous behavior and can actively seek out eye contact, respond to touch and stroke (e.g., moving his tail and flipper), cuddle with people, respond to sounds and the human voice, and (after a while) learn names, including its own.

Figure 3. Paro

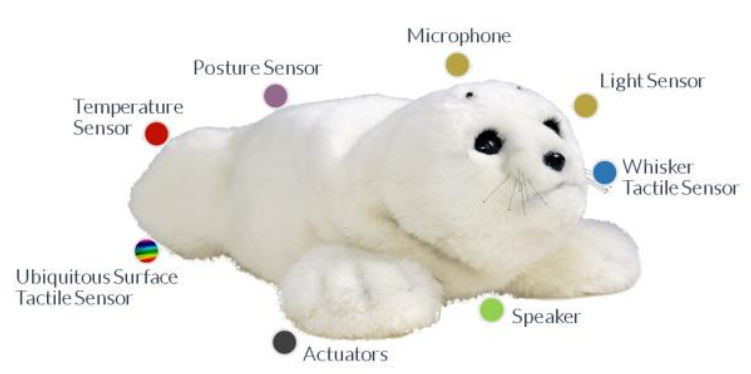

\section{Context and Participants}

The study on the field was performed at a day-time care center in Milano and involved: 5 NDD subjects, whose profile is described in Table II (The functioning level is defined according the diagnosis and the observable functional behavior within the range [1-10]); 5 experienced phycologists or special educators who have worked on a regular base with the subjects for at least one year; 2 members of our technical team.

TABLE II. PARTICIPANTS' PROFILE

\begin{tabular}{|c|c|c|c|}
\hline $\begin{array}{c}\text { Subject } \\
\text { ID }\end{array}$ & Pathology & $\begin{array}{c}\text { Chronological } \\
\text { Age }\end{array}$ & $\begin{array}{c}\text { Functioning } \\
\text { Level }\end{array}$ \\
\hline S1 & $\begin{array}{c}\text { Rare genetic disease } \\
\text { and autistic spectrum } \\
\text { disorder symptoms }\end{array}$ & 17 & 2 \\
\hline S2 & $\begin{array}{c}\text { Down syndrome and } \\
\text { autistic spectrum } \\
\text { disorder symptoms }\end{array}$ & 30 & 3 \\
\hline S3 & $\begin{array}{c}\text { Intellectual disability } \\
\text { and Psychosis }\end{array}$ & 25 & 5 \\
\hline S4 & $\begin{array}{c}\text { Genetic disease and } \\
\text { autistic spectrum } \\
\text { disorder symptoms }\end{array}$ & 29 & 4 \\
\hline S5 & Psychosis & 19 & 4 \\
\hline
\end{tabular}

The physical setting was a room ( $8 \mathrm{sqm})$ familiar to the subjects, but not associated to any specific everyday activity nor structured in a special way for the study purpose. The only furniture of the room were white armchairs, a black table, two windows and some paintings.

\section{Procedure}

Each participant attended one session that followed the protocol reported in this section. All sessions were video recorded.

In the introductory phase, which took place outside the room for 3-5 minutes, the person's caregiver explained to the subject that (s)he was going to meet new friends, robots and humans. The technical team members introduced themselves with the reassuring presence of the caregiver, and chatted with the subject for a while.

Then the subject entered the room, and was invited to take a seat or move into the space according to their will. When the person was seated and looked comfortable, the robots were showed - one after the other. Each robot was placed on the table in front of the subject while the others remain hidden. 
Figure 4. Interacting with Sam (left), Teo (middle) and Paro (right)
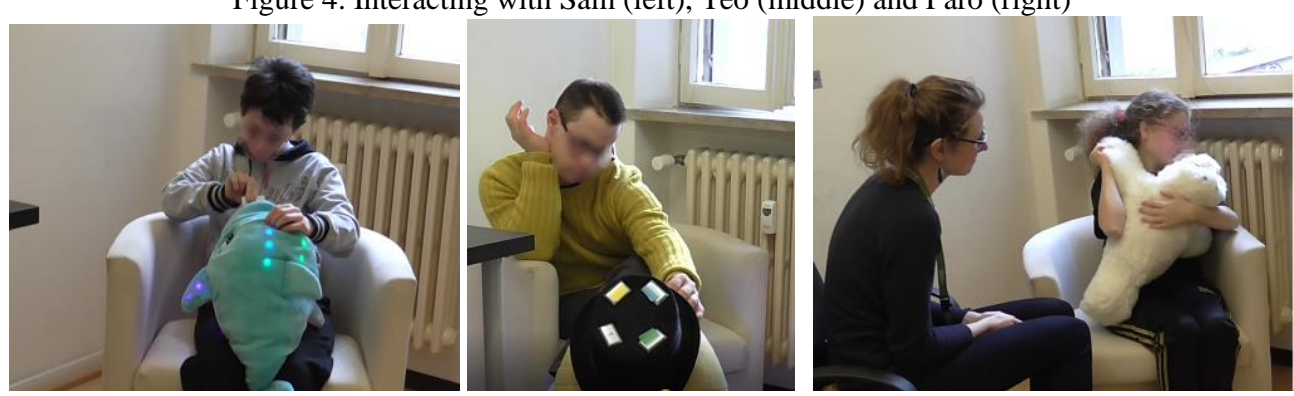

The technical persons and the subject's caregiver invited the subject to play freely with the robot and explore it as (s)he desired. They sat side by side the subject but did not interfere with the robot experience in any form.

The average duration for the entire session with all three robots was planned to last from 10 to 12 minutes. The exposure to an individual robot was planned to last for 3-5 minutes. Still, when it happened that the subject showed an evident decrease in engagement or any sign of distress, the current robot was removed and replaced with the next one, up to the end of the session. This approach, avoiding specific requests or instructions during the exposure time to the intervention, was intended to spur an autonomous exploration of the robot and an active reaction to the robot stimuli.

The order of the robot presentation was defined by the specialists: 1) Sam; 2) Teo, and 3) Paro.

Interacting with Sam was considered a good starting point to help the subject familiarize with the new situation. Sam is not mobile and can be hold on the legs; it is soft and can be easily hugged; it offers light, sound and vibration stimuli. For these reasons it is attractive, fits in the person's main visual focus, and represents a reassuring presence.

Teo is soft and offers similar stimuli, but the experience with this robot is more complex than those with Sam. Teo is much bigger and, above all, can perform movements in the space. Mobility can be an attractive feature. Still, the robot's movement may be distracting and the subject may loose attention to the visual-sound stimuli emitted by Teo. In other word, the stimuli emitted by Teo take place in the space of the room and require a more complex cognitive processing.

Paro was considered appropriate for the last phase, when the subject is potentially tired, and would need to relax and receive a pleasurable reward: Its fur and shape are pleasurable; its interactive affordances are simpler than the ones of Sam and Teo, and it provides less stimuli (vibration and sound, but no light).

\section{RESULTS}

The video recordings of all sessions (approximately 75 minutes) were analyzed by a therapist who did not participate in the sessions. For each subject, she used the behaviors described in Table I as coding schema, identifying the startend time (in minutes: seconds) of each behavior and the Point of Engagement moments (Latency Time) for each robot.

\section{A. Main Data}

From video analysis, we derived the values reported for Latency time (in seconds - Table III) and the results on Engagement reported in Tables $I V$ and $V$, and in Plots $I-V$.

TABLE III: LATENCY TIME (POINT OF ENGAGEMENT)

\begin{tabular}{|c|c|c|c|}
\hline Subject & SAM & TEO & PARO \\
\hline S1 & $25 \mathrm{~s}$ & $4 \mathrm{~s}$ & $10 \mathrm{~s}$ \\
\hline S2 & $30 \mathrm{~s}$ & - & $16 \mathrm{~s}$ \\
\hline S3 & $14 \mathrm{~s}$ & $10 \mathrm{~s}$ & $30 \mathrm{~s}$ \\
\hline S4 & $12 \mathrm{~s}$ & $17 \mathrm{~s}$ & $11 \mathrm{~s}$ \\
\hline S5 & $4 \mathrm{~s}$ & $6 \mathrm{~s}$ & $8 \mathrm{~s}$ \\
\hline
\end{tabular}

TABLE IV: SUSTAINED ENGAGEMENT FOR ROBOT X. TD: TOTAL DURATION (MM.SS). ED: SUSTAINED ENGAGEMENT DURATION (MM.SS). E\%: SUSTAINED ENGAGEMENT IN PERCENTAGE.

\begin{tabular}{|l|l|l|l|l|l|l|l|l|l|}
\hline \multirow{2}{*}{} & \multicolumn{3}{|c|}{ SAM } & \multicolumn{3}{c|}{ TEO } & \multicolumn{3}{c|}{ PARO } \\
\cline { 2 - 10 } & TD & ED & E\% & TD & ED & E\% & TD & ED & E\% \\
\hline S1 & 4.00 & 3.35 & 89,6 & 4.00 & 3.26 & 85,8 & 3.25 & 3.08 & 91,7 \\
\hline S2 & 2.15 & 1.28 & 65,2 & 1.57 & 0.00 & 0 & 2.18 & 1.39 & 71,7 \\
\hline S3 & 3.10 & 2.56 & 92,6 & 3.20 & 3.10 & 95 & 3.30 & 3.00 & 85,7 \\
\hline S4 & 2.17 & 1.54 & 83,2 & 3.52 & 3.45 & 97 & 1.33 & 0.59 & 63,4 \\
\hline S5 & 3.12 & 2.14 & 69,8 & 3.50 & 3.44 & 97,4 & 3.08 & 2.25 & 77,1 \\
\hline
\end{tabular}

TABLE V: SUSTAINED ENGAGEMENT (IN \%) FOR EACH ROBOT W.R.T.TOTAL ENGAGEMENT (TE) IN THE WHOLE SESSION.

TD: TOTAL DURATION (MM.SS) OF THE SESSION.

TE: SUSTAINED ENGAGEMENT DURATION (MM.SS). E\%: SUSTAINED ENGAGEMENT IN PERCENTAGE.

\begin{tabular}{|c|c|c|c|c|c|c|}
\hline \multirow{2}{*}{ Subject } & \multirow{2}{*}{$\begin{array}{c}\text { SAM } \\
\text { E \% }\end{array}$} & \multirow{2}{*}{ TEO } & \multirow{2}{*}{ E \% } & \multirow{2}{*}{ EARO } & \multicolumn{3}{|c|}{ TOTAL } \\
\cline { 5 - 7 } & & & & TD & TE & TE\% \\
\hline S1 & 31,34 & 30,03 & 27,41 & 11.26 & 10.09 & 88,78 \\
\hline S2 & 22,56 & 0 & 25,38 & 6.30 & 3.07 & 47,95 \\
\hline S3 & 29,33 & 31,67 & 30 & 10 & 9.06 & 91 \\
\hline S4 & 24,68 & 48,70 & 12,77 & 7.42 & 6.38 & 86,15 \\
\hline S5 & 21,97 & 36,72 & 23,77 & 10.10 & 8.23 & 82,46 \\
\hline
\end{tabular}

Table IV reports the Total Duration TD (mm.ss) of the experience of each subject with a specific robot, starting from the Point of Engagement. Table IV also shows 2 different values for Sustained Engagement for each robot and subject. $E D$ (Engagement Duration in mm.ss) is the sum of the durations of all engagement behaviors with a robot. E\% provides the same value as a percentage of the Total Duration.

Table $V$ shows, for each robot and subject, the values of Sustained Engagement as a percentage of the Total 
Engagement (TE) during the all session, i.e., the sum of the durations of all engagement behaviors. The table also reports the Total Duration of a session (mm.ss) and Total Engagement TE as absolute value and as percentage of the Total Duration.

PLOT I. Behavior Flow for Subject 1

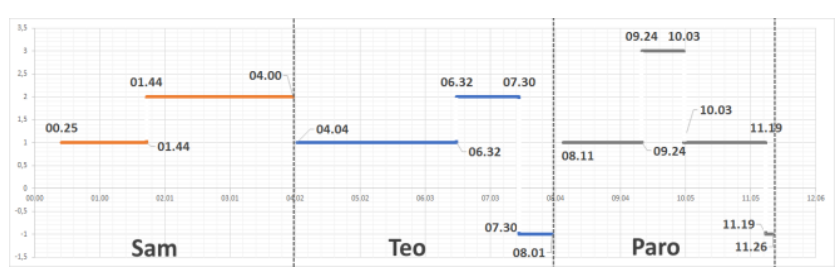

PLOT II. Behavior Flow for Subject 2

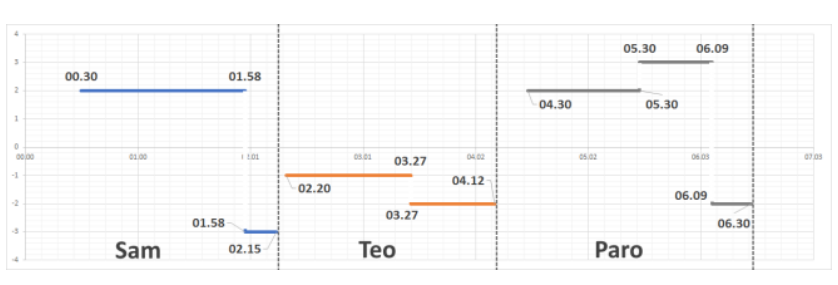

PLOT III. Behavior Flow for Subject 3

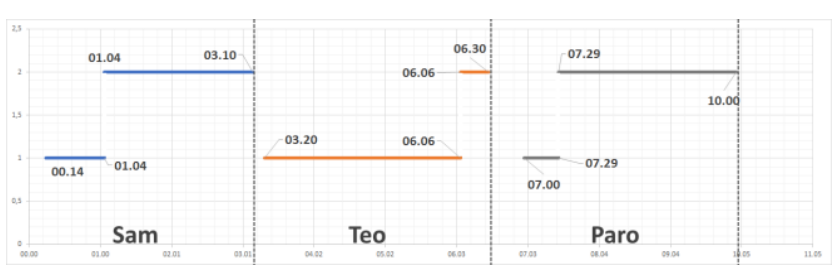

PLOT IV.Behavior Flow for Subject 4

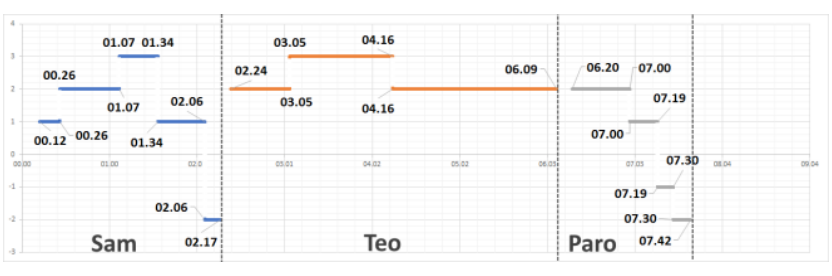

PLOT V. Behavior Flow for Subject 5

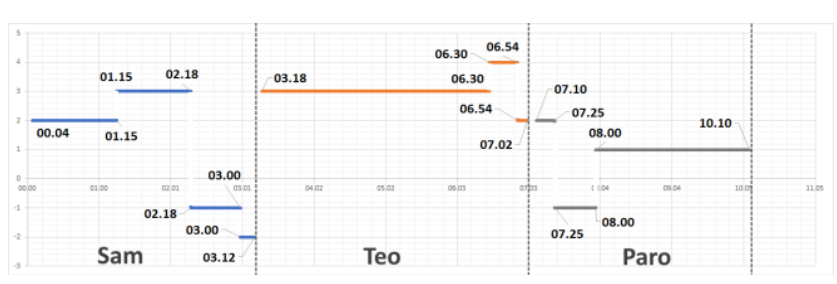

Plots $I-V$ describe the evolution of engagement/disengagement behaviors along the time for each subject and with each robot. In plotting these data, we associated a weight (or level) to each engagement/disengagement behavior, which correspond to a level of intensity of engagement/disengagement. Weights are in the range $[-3 ;+4]$; negative values are associated to disengagement. In order to take into account the impairments of each person and better compare the results among the participants, the mapping "behavior $\rightarrow$ weight (level)" for engagement was not the same for all subjects (as we discussed for Point of Engagement in the previous section). For example, "maintaining visual contact with a robot" is considered a signal of engagement for a subject with a severe form of autism (S2) but not for the other participants. The weights associated to each behavior for each subject are reported in Table VI.

TABLE VI: ENGAGEMENT-DISENGAGEMENT BEHAVIORS RANGE AND ASSOCIATED WEIGHTS BY SUBJECT

\begin{tabular}{|c|c|c|c|c|c|}
\hline Engagement Behaviors & S1 & S2 & S3 & $\mathbf{S 4}$ & S5 \\
\hline $\begin{array}{l}\text { Interacts with a purpose, e.g., } \\
\text { waves the robot, shakes it, or talks, } \\
\text { expecting a reaction }\end{array}$ & & & & & 4 \\
\hline $\begin{array}{l}\text { Holds the robot with both hands } \\
\text { and manifests an arousing of } \\
\text { positive emotions (e.g., laughs and } \\
\text { smiles) }\end{array}$ & 4 & & 4 & 4 & 3 \\
\hline $\begin{array}{l}\text { Grabs and hugs the robot with both } \\
\text { hands and manifests positive } \\
\text { emotions (e.g., smiles) }\end{array}$ & 3 & 4 & 3 & 3 & 2 \\
\hline $\begin{array}{l}\text { Moves the robot into the personal } \\
\text { space, and explores physical } \\
\text { contact }\end{array}$ & 2 & 3 & 2 & 2 & 1 \\
\hline $\begin{array}{l}\text { Sustains a visual contact with the } \\
\text { robot and manifest minimal } \\
\text { physical contacts, e.g., touches and } \\
\text { caresses }\end{array}$ & 1 & 2 & 1 & 1 & \\
\hline $\begin{array}{l}\text { Looks at the robot and sustains a } \\
\text { visual contact with it }\end{array}$ & & 1 & & & \\
\hline \multicolumn{6}{|l|}{ Disengagement behaviors } \\
\hline Doesn't pay attention to the robot & -1 & -1 & -1 & -1 & -1 \\
\hline $\begin{array}{l}\text { Ignores the robot and manifests } \\
\text { irritation or frustration }\end{array}$ & -2 & -2 & -2 & -2 & -2 \\
\hline Pushes the robot away & -3 & -3 & -3 & -3 & -3 \\
\hline
\end{tabular}

The lines in the plots show, for each subject, the engagement/disengagement levels (vertical axis) along the time (horizontal axis). They are tagged with 2 time values that denote the start/end of the behavior, and the line length corresponds to behavior duration.

\section{B. Discussion}

The participants in this study are subjects with impairments in social relations and very little and poor interest in everyday life interaction; they are usually resistant to get involved in most of the proposed activities at the center, to maintain a basic level of attention or to manifest signals of response to commonly used treatment stimuli. For such a target, it is extremely difficult to "draw them in" during regular therapeutic activities. The results of our study show that in these subjects all the three robots had, at different degrees, the power of activating responses, attracting attention and triggering arousal through unstructured stimulation.

According to the specialists, the positive effects of the interaction with Sam, Teo, and Paro emerges from several data and should be considered in light of the subjects' behavior during regular treatment or everyday life situations. Compared with the latency time that these subjects normally have when exposed to a social stimulus for the first time, the time values shown in Table III are very short. The maximum value of latency time is 30 s in subject S2 with Sam. Still, the latency of the same subject with Paro is much lower (16s). S2 has the most severe form of autism among all participants and strong impairments in the social sphere as well as a psychological rigidity towards any new entity. This was evident in the initial phase with Sam but decreases as the session evolved, resulting 
in a lower latency value in the third phase of the session (with Paro).

Concerning engagement and disengagement periods, although findings are no homogeneous among all participants due to their different disorders and severity levels, singleperformance analysis shows a coherent and potentially promising trend. By considering data using percentage values, in Tables IV and $\mathrm{V}$ we can observe that some engagement was achieved by all subjects, and with all robots by all subjects except S2. Percentage data about sustained engagement duration per robot (w.r.t. total amount of time of exposure to a robot) are in the range between $63,44 \%$ (which corresponds to Paro and subject S4) and 97,39\%. These findings denote a degree of engagement much higher than the one normally occurring in regular therapeutic interventions (where $50 \%$ is considered a good achievement).

In Table $V$, the total time of observable engagement for a single robot (in percentage w.r.t. average session duration of 12 minutes) ranges between $21.56 \%$ (Sam, subject S5) and $48.70 \%$ (Teo, subject S4). This means that even the robot that had the lowest engagement score (Sam) was able to attract and trigger attention for approximately $21 \%$ of the total session, which therapists consider a positive result.

The duration data shown in Plots I-V highlight some interesting issues. All subject but $S 2$ moved all robots into the personal space, and performed various forms of exploratory physical contact. Allowing an object to enter the personal space, and manipulating it, is an important signal of trust and confirms that the physical attributes of all these robots, such as fabric, color, weight and shape are compatible with this type of subjects. S2 deserves some further considerations. This subject reached and maintained an engagement state with Sam and Paro, but, as highlighted also in Table V, he did not manifest any form of engagement (or disengagement) when exposed to Teo. The most peculiar characteristics of Teo are its big size and mobility. For its dimensions, Teo resembles more a human figure than a puppy, and may have triggered a state of anxiety that any new person initially causes to S2 (and in general, to most subjects with severe forms of autism and social impairments). In addition, even if Teo remained in the "external" space [22] (i.e., outside the personal space) and had no physical contact with the subject, its presence was probably perceived as invasive, and its capability of moving and entering the personal space was felt as potentially dangerous. We hypothesize that S2 would have need a longer period of familiarization with Teo to mitigate this condition. Still, investigating if and at which degree size and mobility of a robot have a correlation with engagement effects in subjects with severe forms of autisms deserves further investigation.

Despite many positive responses, some subjects (S3, S4, S5) seemed to suffer a certain fatigue during the session as they had longer latency time while they experienced the last robot. This phenomenon is coherent with the pathology. It is very frequent in these subjects that the exposure to a new stimulus and context creates loss of attention, and distraction increases (as well as the fatigue to control it) as the exposure to a new stimulus proceeds. Engagement seems to drop for all subjects with all robots after $1.35 \mathrm{~s}$ of interaction; in other words, after this time the stimuli generated by the robot tend to create a disengagement state. This result may indicate that without a feedback from the robot or a structured supervised use of it, around this moment the subject would lose interest to the experience, which would become ineffective. This in turn suggests the need to define a standardized protocol of intervention in terms not only of sequence of stimuli to administer but also of caregivers' re-enforcement actions during the robotic experience.

\section{Limitations}

Our study is exploratory and certainly does not meet the requirements of evidence-based research. It has a number of limitations and results should be taken with caution. The number of participants is small (like most of the reported studies mentioned in Section II). There is a variability between the participants in terms of age, impairments, and severity of the disorders. Persons with NDD, but with different needs and abilities from those who participated in the study may not manifest similar engagement/disengagement trends. Subjects on the NDD spectrum also vary their behavior significantly based on the physical and social context, and conducting similar activities in different situations might yield different results. We involved the subjects in one session only where the three robots were presented in the same order. A deeper analysis of our data is needed to discover any relationship between participant's behavioral signals and the stimuli emitted by the robots, and to identify if and at which degree some engagement/disengagement effects can be ascribed to specific design features of the robots and to the order of presentation. We may also wonder if positive results could simply be ascribed to the "novelty effect". The answer is "probably not". For all subjects involved in our study (like for many people with NDD), the "unknown" is often a source of distress and discomfort and these persons tend to manifest rigidity towards any new situation. Novelty therefore should not be considered a facilitator of engagement.

\section{CONCLUSIONS AND FUTURE WORK}

The study reported in this paper is part a long-term research that investigates the learning processes that social robots would promote among persons with NDD [2][5]. We focused on the engagement process - the preliminary and necessary phase of any learning process among this target group. Our study considered three robots and five subjects with NND who experienced the robotic companions, one after the other, during one individual session.

Our findings show that (in different forms) all robots engaged all participants, and confirm the results of previous studies that indicate the potential of social robots to trigger engagement among individuals with NDD. To analyze participants' behaviors, we have exploited an interpretation schema that is based on an accurate range of engagementdisengagement signals and on weights associated to behavioral signal according to the characteristics of each individual. To our knowledge, this methodological framework for engagement analysis is novel and may help other researchers who want to explore the effects of SAR among subjects with NDD.

The next step in our research agenda is a wider and more rigorous empirical study lasting for several weeks. We have defined an experimental protocol which envisions a randomized order of robot presentation and have recruited a 
wider number of participants (organized into more homogenous groups).

\section{ACKNOWLEDGMENTS}

The authors warmly thank the participants to this study and their families.

\section{REFERENCES}

[1] Billard, A., Robins, B., Nadel, J. and Dautenhahn, K., 2007. Building robota, a mini-humanoid robot for the rehabilitation of children with autism. Assistive Technology, 19(1), pp.37-49.

[2] Bonarini, A., Garzotto, F., Gelsomini, M., Romero, M., Clasadonte, F. and Yilmaz, A.N.Ç., 2016, August. A huggable, mobile robot for developmental disorder interventions in a multi-modal interaction space. In Robot and Human Interactive Communication (RO-MAN), 2016 25th IEEE International Symposium on (pp. 823-830). IEEE.

[3] Cabibihan, J.J., Javed, H., Ang, M. and Aljunied, S.M., 2013. Why robots? A survey on the roles and benefits of social robots in the therapy of children with autism. International journal of social robotics, 5(4), pp.593-618.

[4] Chapman, P.M., 1997. Models of engagement: Intrinsically motivated interaction with multimedia learning software (Doctoral dissertation, University of Waterloo).

[5] Colombo, S., Garzotto, F., Gelsomini, M., Melli, M. and Clasadonte, F., 2016, June. Dolphin Sam: A Smart Pet for Children with Intellectual Disability. In Proceedings of the International Working Conference on Advanced Visual Interfaces (pp. 352-353). ACM.

[6] Dautenhahn, K., Werry, I., Salter, T. and Boekhorst, R.T., 2003, July. Towards adaptive autonomous robots in autism therapy: Varieties of interactions. In Computational Intelligence in Robotics and Automation, 2003. Proceedings. 2003 IEEE International Symposium on (Vol. 2, pp. 577-582). IEEE.

[7] Den Brok, W.L.J.E. and Sterkenburg, P.S., 2015. Self-controlled technologies to support skill attainment in persons with an autism spectrum disorder and/or an intellectual disability: a systematic literature review. Disability and Rehabilitation: Assistive Technology, pp.1-10.

[8] Diehl, J.J., Schmitt, L.M., Villano, M. and Crowell, C.R., 2012. The clinical use of robots for individuals with autism spectrum disorders: A critical review. Research in autism spectrum disorders, 6(1), pp.249-262.

[9] Duquette, A., Michaud, F. and Mercier, H., 2008. Exploring the use of a mobile robot as an imitation agent with children with lowfunctioning autism. Autonomous Robots, 24(2), pp.147-157.

[10] Feil-Seifer, D. and Mataric, M.J., 2005, June. Defining socially assistive robotics. In Rehabilitation Robotics, 2005. ICORR 2005. 9th International Conference on (pp. 465-468). IEEE.

[11] Feil-Seifer, D. and Mataric, M.J., 2008, August. B 3 IA: A control architecture for autonomous robot-assisted behavior intervention for children with Autism Spectrum Disorders. In Robot and Human Interactive Communication, 2008. RO-MAN 2008. The 17th IEEE International Symposium on (pp. 328-333). IEEE.

[12] Ferrara, C. and Hill, S.D., 1980. The responsiveness of autistic children to the predictability of social and nonsocial toys. Journal of autism and developmental disorders, pp.51-57.

[13] Fong, T., Nourbakhsh, I. and Dautenhahn, K., 2003. A survey of socially interactive robots. Robotics and autonomous systems.

[14] Garzotto, F. and Bordogna, M., 2010, June. Paper-based multimedia interaction as learning tool for disabled children. In Proceedings of the 9th ACM international Conference on Interaction Design and Children

[15] Kozima, H., Michalowski, M.P. and Nakagawa, C., 2009. Keepon. International Journal of Social Robotics, 1(1), pp.3-18.

[16] Marti, P., Pollini, A., Rullo, A. and Shibata, T., 2005, September. Engaging with artificial pets. In Proceedings of the 2005 annual conference on European association of cognitive ergonomics (pp. 99106). University of Athens.

[17] Michaud, F., Duquette, A. and Nadeau, I., 2003, October. Characteristics of mobile robotic toys for children with pervasive developmental disorders. In Systems, Man and Cybernetics, 2003. IEEE International Conference on (Vol. 3, pp. 2938-2943). IEEE.

[18] Michaud, F., Salter, T., Duquette, A. and Laplante, J.F., 2007. Perspectives on mobile robots as tools for child development and pediatric rehabilitation. Assistive Technology, 19(1), pp.21-36.

[19] O'Brien, H.L. and Toms, E.G., 2008. What is user engagement? A conceptual framework for defining user engagement with technology. Journal of the American Society for Information Science and Technology, 59(6), pp.938-955.

[20] Piaget, J., 2013. Play, dreams and imitation in childhood (Vol. 25) Routledge.

[21] Ravichandran, S., Jacklyn, H.Q., 2009. Behavior modification strategy for motivating children with attention deficiency disorder. In Proc. of Int. Conv. on Rehabilitation Engineering \& Assistive Technology, 35. ACM.

[22] Rizzolatti G, Fadiga L, Fogassi L, Gallese V. The space around us. Science. 1997;277:190-191

[23] Ricks, D.J. and Colton, M.B., 2010, May. Trends and considerations in robot-assisted autism therapy. In Robotics and Automation (ICRA), 2010 IEEE International Conference on (pp. 4354-4359). IEEE.

[24] Robins, B., Dautenhahn, K., Ferrari, E., Kronreif, G., Prazak-Aram, B., Marti, P., Iacono, I., Gelderblom, G.J., Bernd, T., Caprino, F. and Laudanna, E., 2012. Scenarios of robot-assisted play for children with cognitive and physical disabilities. Interaction Studies, pp.189-234.

[25] Robins, B., Dautenhahn, K., Te Boekhorst, R. and Billard, A., 2005. Robotic assistants in therapy and education of children with autism: can a small humanoid robot help encourage social interaction skills? Universal Access in the Information Society, 4(2), pp.105-120.

[26] Sabanovic, S., Bennett, C.C., Chang, W.L. and Huber, L., 2013, June. PARO robot affects diverse interaction modalities in group sensory therapy for older adults with dementia. In Rehabilitation Robotics (ICORR), 2013 IEEE International Conference on (pp. 1-6). IEEE

[27] Salter, T., Davey, N. and Michaud, F., 2014, August. Designing \& developing QueBall, a robotic device for autism therapy. In Robot and Human Interactive Communication, 2014 RO-MAN: The 23rd IEEE International Symposium on (pp. 574-579). IEEE.

[28] Salter, T., Michaud, F. and Larouche, H., 2010. How wild is wild? A taxonomy to characterize the 'wildness' of child-robot interaction. International Journal of Social Robotics, 2(4), pp.405-415.

[29] Scassellati, B., 2007. How social robots will help us to diagnose, treat, and understand autism. In Robotics research (pp. 552-563). Springer Berlin Heidelberg.

[30] Scassellati, B., Admoni, H. and Matarić, M., 2012. Robots for use in autism research. Annual review of biomedical engineering, 14, pp.275-294.

[31] Shamsuddin, S., Yussof, H., Ismail, L., Hanapiah, F.A., Mohamed, S., Piah, H.A. and Zahari, N.I., 2012, March. Initial response of autistic children in human-robot interaction therapy with humanoid robot NAO. In Signal Processing and its Applications (CSPA), 2012 IEEE 8th International Colloquium on (pp. 188-193). IEEE.

[32] Shibata, T., Mitsui, T., Wada, K. and Tanie, K., 2002. Subjective evaluation of seal robot: Paro-tabulation and analysis of questionnaire results. Journal of Robotics and Mechatronics, 14(1), pp.13-19.

[33] Shibata, T., Mitsui, T., Wada, K., Touda, A., Kumasaka, T., Tagami, K. and Tanie, K., 2001. Mental commit robot and its application to therapy of children. In Advanced Intelligent Mechatronics, 2001 Proceedings. 2001 IEEE/ASME International Conference

[34] Tapus, A., Peca, A., Aly, A., Pop, C., Jisa, L., Pintea, S., Rusu, A.S. and David, D.O., 2012. Children with autism social engagement in interaction with Nao, an imitative robot: A series of single case experiments. Interaction studies, 13(3), pp.315-347.

[35] Zuckerman, O., Hoffman, G., Kopelman-Rubin, D., Klomek, A.B., Shitrit, N., Amsalem, Y. and Shlomi, Y., 2016, February. KIP3: Robotic Companion As an External Cue to Students with ADHD. In Proceedings of the TEI'16: Tenth International Conference on Tangible, Embedded, and Embodied Interaction (pp. 621-626). ACM.

[36] Billard, A., Robins, B., Nadel, J. and Dautenhahn, K., 2007. Building robota, a mini-humanoid robot for the rehabilitation of children with autism. Assistive Technology, pp.37-49. 